\title{
EFEKTIFITAS PENYELENGGARAAN PROGRAM BEASISWA BIDIKMISI DI UNIVERSITAS PENDIDIKAN GANESHA
}

\author{
KOMANG DANDY ANDRIADI, ETHYA TRE WIDHY ASIH, A.A. WIKA DEWI, K. \\ NUGRAHA, I MADE DEVA SAMADHINATA \\ Jurusan Akuntansi, Universitas Pendidikan Ganesha, Singaraja, Bali, Indonesia
}

\begin{abstract}
Abstrak
Penelitian ini bertujuan untuk mengetahui proses penyeleksian Program Beasiswa Bidikmisi di Universitas Pendidikan Ganesha, bagaimana pengelolaan Program Beasiswa Bidikmisi di Universitas Pendidikan Ganesha, bagaimana pengawasan Program Beasiswa Bidikmisi di Universitas Pendidikan Ganesha. Metode penelitian ini yaitu metode kualitatif dengan teknik pengumpulan data melalui waancara. Penelitian ini belokasi di Universitas Pendidikan Ganesha Singaraja. Sumber data berasal dari data primer dan data sekunder. Hasil dari penelitian ini yaitu penyelengaraan program beasiswa bidikmisi di Universitas Pendidikan Ganesha (UNDIKSHA) belum sepenuhnya efektif. Adapun kendala-kendala ynag dihadapi dari masing-masing informan diantaranya: Kurangnya pemahaman mengenai program beasiswa bidikmisi, kurangnya forum komunikasi, serta adanya kewajiban untuk membuat PKM bagi mahasiswa penerima bidikmisi.
\end{abstract}

Kata kunci: Efektivitas, Penyelenggaraan, Beasiswa Bidikmisi

\begin{abstract}
This study aims to determine the process of selecting the Bidikmisi Scholarship Program at the Ganesha Educational University, how to manage the Bidikmisi Scholarship Program at the Ganesha Education University, how to supervise the Bidikmisi Scholarship Program at the Ganesha Educational University. This research method is a qualitative method with data collection techniques through interviews. This research is located in the Ganesha Singaraja Educational University. Source of data comes from primary data and secondary data. The results of this study are that the bidikmisi scholarship program at Ganesha University of Education (UNDIKSHA) has not been fully effective. The constraints faced by each informant include: Lack of understanding of the Bidikmisi scholarship program, lack of communication forums, and the existence of an obligation to create a PKM for Bidikmisi recipient students.
\end{abstract}

Keywords: Effectiveness, Implementation, Bidikmisi Scholarship

\section{Pendahuluan}

Pendidikan merupakan hal yang sangat penting bagi peningkatan taraf kehidupan. Sudah selayaknya masyarakat mengedepankan pendidikan sebagai salah satu unsur yang ada dalam diri kita. Pendidikan tinggi merupakan bagian terpenting untuk menghasilkan sumber daya yang kompetitif dan professional pada bidangnya agar mampu bersaing secara global. Hal tersebut tercermin didalam Undang-Undang Republik Indonesia Nomor 12 Tahun 2012 tentang Sistem Pendidikan Tinggi, sebagaimana dijelaskan dalam pasal 5 dimana tujuan pendidikan tinggi adalah "dihasilkannya lulusan yang menguasai cabang IImu pengetahuan dan, atau teknologi untuk memenuhi kepentingan nasional dan peningkatan daya saing bangsa" (Eldrian, 2017).

Pemerintah melalui Direktorat Jenderal Pembelajaran dan Kemahasiswaan, Kementerian Riset Teknologi dan Pendidikan Tinggi mulai tahun 2010 meluncurkan Program Bantuan Biaya Pendidikan Bidikmisi (Sandra, 2017). Program Bidikmisi merupakan salah satu program unggulan pemerintah yang bertujuan untuk meningkatkan akses dan kesempatan belajar di Perguruan Tinggi bagi peserta didik yang tidak mampu secara ekonomi dan memiliki prestasi akademik yang baik. 
Dikutip dari situs resmi Riset Teknologi dan Pendidikan Tinggi (ristekdikti.go.id), sampai dengan tahun 2017 tercatat lebih dari 432.409 mahasiswa yang telah memperoleh bantuan biaya pendidikan Bidikmisi, dari jumlah tersebut sebanyak 145.000 telah menyelesaikan pendidikannya. Jumlah peminat Program Bidikmisi menunjukkan peningkatan yang sangat signifikan dari tahun ke tahun, untuk tahun 2017 tercatat sebanyak 520.688 pelamar tetapi hanya sekitar 80.000 saja yang bisa diakomodir karena keterbatasan anggaran pemerintah. Dari segi prestasi, para mahasiswa Bidikmisi juga menunjukkan kemampuan akademik yang luar biasa dengan capaian IPK lebih dari 87\% mahasiswa Bidikmisi memperoleh IPK di atas antara 3,0. Dengan demikian para mahasiswa Bidikmisi turut berkontribusi terhadap peningkatan mutu pendidikan disetiap perguruan tinggi. Bidikmisi diberikan kepada penerima selama 8 (delapan) semester untuk S1 atau D4, 6 (enam) semester untuk D3, 4 (empat) semester untuk D2, dan 2 (dua) semester untuk D1. Besaran subsidi biaya hidup yang diberikan serendah-rendahnya Rp650.000,00 per bulan diberikan setiap 6 bulan. Adapun pembebasan biaya pendidikan mencakup semua biaya yang dibayarkan ke Perguruan Tinggi untuk kepentingan pendidikan.

Berdasarkan pada buku Panduan Bidikmisi 2018 yang diterbitkan oleh Direktorat Jendral Pembelajaran dan Kemahasiswaan, Kemenristekdikti, adapun persyaratan calon penerima bidikmisi adalah sebagai berikut.

1. Siswa SMA/SMK/MA/MAK atau bentuk lain yang sederajat yang akan lulus pada tahun 2018 dan 2017;

2. Belum pernah ditetapkan sebagai penerima Bidikmisi di perguruan tinggi;

3. Usia paling tinggi pada saat diterima di perguruan tinggi adalah 21 tahun;

4. Tidak mampu secara ekonomi dengan kriteria:

a. Siswa penerima Kartu Indonesia Pintar (KIP) atau sejenisnya;

b. Pendapatan kotor orang tua/wali gabungan (suami + istri) setinggitingginya Rp4.000.000,00 (Empat juta rupiah) atau pendapatan kotor gabungan orang tua/wali dibagi jumlah anggota keluarga maksimal Rp750.000,00 (Tujuh ratus lima puluh ribu rupiah).

5. Pendidikan orang tua/wali setinggi-tingginya S1 (Strata 1) atau Diploma4;

6. Memiliki potensi akademik baik berdasarkan rekomendasi objektif dan akurat dari Kepala Sekolah;

7. Pendaftar difasilitasi untuk memilih salah satu di antara PTN atau PTS dengan ketentuan:

a. PTN dengan pilihan seleksi masuk:

1) Seleksi Masuk Perguruan Tinggi Negeri (SNMPTN);

2) Seleksi Bersama Masuk Perguruan Tinggi Negeri (SBMTPN);

3) Seleksi Mandiri PTN.

b. Politeknik, UT, dan Institut Seni dan Budaya;

c. PTS sesuai dengan pilihan seleksi masuk.

Berdasarkan tulisan yang diposting oleh Harian Nasional (www.harnas.co), menyatakan bahwa realisasi Program Bidikmisi dari tahun ke tahun masih kurang efektif. Parameter ketidaktepatan ini diukur berdasarkan prinsip 3T (tepat sasaran, tepat jumlah, dan tepat waktu). Observasi awal pada 3 (tiga) orang penerima beasiswa Bidikmisi di Universitas Pendidikan Pendikan Ganesha menunjukkan indikasi bahwa kemungkinan ada ketidaktepatan sasaran. Responden pertama mengungkap bahwa memang benar data-data persyaratan untuk melamar beasiswa Bidikmisi dimanipulasi sedemikian rupa agar memenuhi kriteria yang telah ditetapkan. Responden kedua mengatakan bahwa dalam pencalonan beasiswa Bidikmisi menggunakan bantuan orang dalam (keluarganya). Responden ketiga mengungkapkan bahwa pencalonan beasiwa Bidikmisi dimaksudkan untuk menambah uang saku atau kepentingan pribadinya walaupun orang tuanya memiliki kemampuan ekonomis di atas rata-rata.

Adapun penelitian terdahulu yang meneliti tentang efektifitas pelaksanaan program beasiswa Bidikmisi diantaranya: (1) Baskoro (2016) mengatakan bahwa kurangnya komitmen dan keseriusan mahasiswa Bidikmisi dalam menjalankan kewajibankewajibannya. (2) Kurniawan (2017) menjelaskan bahwa Program Bidikmisi di Universitas X 
kurang bermanfaat akibat dari faktor mahasiswa itu sendiri. (3) Rahmawati (2016) mengungkapkan adanya indikasi pola prilaku konsumtif pada mahasiswa Bidikmisi namun dengan tingkat hubungan yang rendah.

Bercermin dari hal tersebut, peneliti ingin mengkaji permasalahan tersebut melalui sebuah penelitian mini (miniresearch) yang berjudul: "Efektifitas Penyelenggaraan Program Beasiswa Bidikmisi di Universitas Pendidikan Ganesha". Penelitian ini dapat digunakan sebagai parameter kasar dalam mengukur efektifitas penyelenggaraan Program Beasiswa Bidikmisi di Universitas Pendidikaan Ganesha berdasarkan pada prinsip 3T.

Berdasarkan permasalahan diatas, rumusan masalah yang dapat dirumuskan yaitu bagaimana proses penyeleksian Program Beasiswa Bidikmisi di Universitas Pendidikan Ganesha, bagaimana pengelolaan Program Beasiswa Bidikmisi di Universitas Pendidikan Ganesha, bagaimana pengawasan Program Beasiswa Bidikmisi di Universitas Pendidikan Ganesha.

\section{Landasan Teori Konsep Efektifitas}

Efektivitas berasal dari kata efektif yang dalam bahasa Inggris effective yang memiliki makna berhasil atau sesuatu yang dilakukan berhasil dengan baik. Sedangkan menurut Hermawat (dalam Baskoro 2016) menyatakan bahwa suatu program dikatakan efektif apabila dapat mencapai tujuan yang diharapkan dan berdampak secara positif bagi sasaran program.

Menurut Edi Suharto (dalam Baskoro, 2016) juga mengungkapkan pendapat yang serupa bahwa efektivitas kebijakan program sosial merupakan suatu keadaan dimana hasil yang diharapkan sesuai dengan tujuan program. Sehingga, dapat diidentifikasikan apakah sebuah program menghasilkan dampak yang bermanfaat bagi masyarakat, apakah dampak yang ditimbulkan program dapat meningkatkan kesejahteraan masyarakat, dan apakah program tersebut dapat mencapi tujuannya.

Dari beberapa defenisi para ahli diatas maka dapat disimpulkan bahwa efektifitas kebijakan merupakan pencapaian keberhasilan sebuah program/kebijakan yang telah disusun atau direncanakan oleh pemerintah yang berlandaskan tujuan untuk mencapai keberhasilan program tersebut. Peneliti dalam hal ini mengkaitkan efektivitas sebagai pencapaian hasil dan tujuan kebijakan program bidikmisi di Universitas Pendidikan Ganesha.

\section{Program Beasiswa Bidikmisi}

Bidikmisi merupakan program pemerintah untuk memberikan akses peendidikan tinggi kepada masyarakat miskin untuk dapat memutus mata rantai kemiskinan. Baskoro (2016) menegaskan bahwa program beasiswa Bidikmisi harus berpedoman pada prinsip 3T (tepat sasaran, tepat jumlah, dan tepat waktu). Berdasarkan pada buku Panduan Bidikmisi 2018 yang diterbitkan oleh Direktorat Jendral Pembelajaran dan Kemahasiswaan, Kemenristekdikti, ada beberapa mekanisme yang harus diperhatikan sehubungan dengan penyelenggaraan program Bidikmisi tahun 2018 diantaranya sebagai berikut.

a. Persyaratan Calon Penerima Bidikmisi

1. Siswa SMA/SMK/MA/MAK atau bentuk lain yang sederajat yang akan lulus pada tahun 2018 dan 2017;

2. Belum pernah ditetapkan sebagai penerima Bidikmisi di perguruan tinggi;

3. Usia paling tinggi pada saat diterima di perguruan tinggi adalah 21 tahun;

4. Tidak mampu secara ekonomi dengan kriteria:

- Siswa penerima Kartu Indonesia Pintar (KIP) atau sejenisnya;

- Pendapatan kotor orang tua/wali gabungan (suami + istri) setinggitingginya Rp4.000.000,00 (Empat juta rupiah) atau pendapatan kotor gabungan orang tua/wali dibagi jumlah anggota keluarga maksimal Rp750.000,00 (Tujuh ratus lima puluh ribu rupiah).

5. Pendidikan orang tua/wali setinggi-tingginya S1 (Strata 1) atau Diploma4;

6. Memiliki potensi akademik baik berdasarkan rekomendasi objektif dan akurat dari Kepala Sekolah; 
7. Pendaftar difasilitasi untuk memilih salah satu di antara PTN atau PTS dengan ketentuan:

- PTN dengan pilihan seleksi masuk:

- Seleksi Masuk Perguruan Tinggi Negeri (SNMPTN);

- Seleksi Bersama Masuk Perguruan Tinggi Negeri (SBMTPN);

- Seleksi Mandiri PTN.

- Politeknik, UT, dan Institut Seni dan Budaya;

- PTS sesuai dengan pilihan seleksi masuk.

b. Mekanisme Pendaftaran

Tata cara pendaftaran Bidikmisi melalui SNMPTN, SBMPTN, PMDK Politeknik atau Seleksi Mandiri Perguruan Tinggi secara online pada laman Bidikmisi (http://bidikmisi.belmawa.ristekdikti.go.id/) adalah sebagai berikut.

1. Tahapan Pendaftaran Bidikmisi.

- Sekolah mendaftarkan diri sebagai institusi pemberi rekomendasi ke laman Bidikmisi dengan melampirkan hasil pindaian (scan) (Lampiran 1 bagian persetujuan dan tanda tangan) untuk mendapatkan nomor Kode Akses Sekolah;

- Direktorat Jenderal Pembelajaran dan Kemahasiswaan memverifikasi pendaftaran dalam kurun waktu 1 x 24 jam pada hari dan jam kerja;

- Sekolah merekomendasikan masing-masing siswa melalui laman Bidikmisi menggunakan kombinasi NPSN dan kode akses yang telah diverifikasi.

- Sekolah memberikan nomor pendaftaran dan kode akses kepada masingmasing siswa yang sudah direkomendasikan;

- Siswa mendaftar melalui laman Bidikmisi dan menyelesaikan semua tahapan yang diminta di dalam sistem pendaftaran.

2. Siswa yang sudah menyelesaikan pendaftaran Bidikmisi mendaftar seleksi nasional atau mandiri yang telah diperoleh sesuai ketentuan masing-masing pola seleksi melalui alamat berikut:

- SNMPTN melalui http://www.snmptn.ac.id

- SBMPTN melalui http://www.sbmptn.ac.id

- PMDK Politeknik melalui http://pmdk.politeknik.or.id

- Seleksi Mandiri PTN sesuai ketentuan masing-masing PTN

- Seleksi Mandiri PTS sesuai ketentuan masing masing PTS

- Siswa yang mendaftar dan ditentukan lolos melalui seleksi masuk. melengkapi berkas, dan berkas dibawa pada saat pendaftaran ulang, yaitu:

- Kartu peserta dan formulir pendaftaran program Bidikmisi yang dicetak dari laman Bidikmisi;

- Kartu Indonesia Pintar (KIP), atau bantuan pemerintah sejenis lainnya (jika ada);

- Siswa yang belum memenuhi syarat butir (b) di atas, harus membawa Surat Keterangan Penghasilan Orang TuaWali atau Surat Keterangan Tidak Mampu yang dapat dibuktikan kebenarannya, yang dikeluarkan oleh Kepala Desa/Kepala Dusun/Instansi tempat orang tua bekerja/tokoh masyarakat;

- Fotokopi Kartu Keluarga atau Surat Keterangan tentang Susunan Keluarga;

- Fotokopi rekening listrik bulan terakhir (apabila tersedia aliran listrik) dan/ atau bukti pembayaran PBB (apabila mempunyai bukti pembayaran) dari orang tua/wali-nya;

- Berkas pendukung lainnya yang diminta oleh perguruan tinggi dan Kopertis.

c. Mekanisme Penetapan

Bagi calon mahasiswa penerima Bidikmisi yang telah dinyatakan diterima di Perguruan Tinggi, akan dilakukan hal-hal sebagai berikut. 
1. Verifikasi kelayakan penerima Bidikmisi oleh perguruan tinggi dan Kopertis.

2. Penetapan mahasiswa penerima Bidikmisi oleh perguruan tinggi dan Kopertis.

\section{Metode Penelitian}

Penelitian ini merupakan penelitian kualitatif. Penelitian kualitatif merupakan penelitian yang digunakan untuk menghasilkan data deskriptif yang ditulis atau yang diucapkan orang dan perilaku-perilaku yang dapat diamatai (Silalahi, 2012). Penelitian ini belokasi di Universitas Pendidikan Ganesha Singaraja.

Informan penelitian merupakan pihak-pihak yang dapat memberikan informasi mengenai situasi dan kondisi yang ada sehingga data yang dihasilkan dapat akurat dan terpercaya (Asra et al., 2015). Data tersebut berupa pernyataan keterangan maupun datadata yang dapat membantu peneliti untuk memahami permasalahan penelitian. Pihak-pihak tersebut diantaranya yaitu mahasiswa penerima beasiswa Bidikmisi semester 2 sebanyak 2 orang (Mahasiswa A dan Mahasiswa B) dan mahasiswa penerima beasiswa Bidikmisi semester 4 sebanyak 2 orang (Mahasiswa $C$ dan Mahasiswa D).

Sumber data berasal dari data primer dan data sekunder. Data primer diperoleh melalui responden melalui wawancara, sedangkan data sekunder diperoleh melalui studi pustaka dari buku-buku literatur, jurnal, maupun tulisan lainnya yang berisi kajian teori yang relevan.

Teknis analisis data menggunakan model Miles dan Huberman (dalam Baskoro, 2016). Model Miles dan Huberman menyebutkan bahwa ada empat alur, yaitu (1) Pengumpulan data; (2) Reduksi data; (3) Display atau Penyajian Data; (4) Penarikan Kesimpulan.

\section{Hasil dan Pembahasan}

Berikut deskripsi data hasil penelitian dari informan mengenai efektifitas program Bidikmisi di UNDIKSHA.

a) Mahasiswa $A$

Berikut ini hasil kutipan wawancara pada mahasiswa $A$.

"Bagi saya bidikmisi ini adalah kehidupan saya di kampus, tanpa bidikmisi, saya tidak akan bisa melanjutkan kuliah saya. Menurut saya program bidikmisi belum tepat sasaran, karena masih ada beberapa mahasiswa yang sangat mampu dan berkecukupan dalam segalanya, masih mendapatkan bidikmisi. Dana yang diperoleh dari bidikmisi, selama ini saya dapatkan sudah sesuai dengan jumlah yang telah dijanjikan. Akan tetapi waktu pemberian dana bidikmisi masih sering tidak tepat waktu. Dan kendala yang saya rasakan dalam pelaksanaan program bidikmisi ini adalah masih banyak mahasiswa menganggap bidikmisi ini hanya sebagai beasiswa untuk gaya hidupnya, sehingga masih banyak mahasiswa yang tidak taat akan peraturan dan membuat PKM sembarangan tanpa motivasi dan inovasi."

b) Mahasiswa B

Berikut ini hasil kutipan wawancara pada mahasiswa B.

"Bagi saya pelaksanaan program bidikmisi sangatlah membantu. Akan tetapi pelaksaan bidikmisi ini masih belum sepenuhnya tepat sasaran. Dana yang diperoleh dari program bidikmisi belum pernah tidak sesuai atau selalu sesuai. Namun waktu pencairan dananya yang masih belum tepat waktu. Dan selama ini menurut saya penyelenggaraan program di undiksha tidak ada kendala."

c) Mahasiswa C

Berikut ini hasil kutipan wawancara pada mahasiswa C.

"Menurut saya kebanyakan bidikmisi tidak digunakan untuk keperluan study, melainkan hanya untuk keperluan pribadi masing masing mahasiswa/l yang memperoleh beasiswa bidikmisi walaupun tidak semuanya seperti itu. Pelaksanaan program bidikmisi ini masih belum tepat sasaran, karena masih ada yang mahasiswa yang sepantasnya tidak menerima bidikmisi karena terbilang kemampuan ekonomi mereka mencukupi. Dan untuk masalah dana yang 
diperoleh dari bidikmisi, saya tidak mengetahui bagaimana jelas tentang perhitungan pembagian bidikmisi, yang terpenting saya menerima bidikmisi yang diberikan pemerintah dan menggunakannya sesuai kepeluan saya selama kuliah. Waktu pemberian dananya kadang tepat waktu dan kadang tidak tepat waktu. Dan kendala yang saya rasakan adalah kurangnya forum komunikasi penerima bidikmisi guna menyampaikan apa saja kegiatan dan informasi seputaran bidikmisi."

d) Mahasiswa D

Berikut ini hasil kutipan wawancara pada mahasiswa D.

"Menurut saya pelaksanaan bidikmisi selama ini sudah sangat membantu mahasiswa dalam masa studinya sebagaimana layaknya fungsi beasiswa pada umumnya. Jika dikatakan tepat sasaran , bisa iya bisa tidak. Beberapa memang tepat sasaran pada mahasiswa yang memang pantas menerima beasiswa bidikmisi karena memang kurang mampudari segi ekonomi, namun beberapa sepertinya ada ketidaktepatan karena ada penerima bidikmisi yang nyata mampu secara ekonomi namun tetap mencari beasiswa bidikmisi yang harusnya bukan untuknya. Dana yang diperoleh dari program bidikmisi sejauh ini dananya sesuai, namun pencairannya saja yang bertahap atau tidak langsung semua dicairkan. Pencairannya terkadang tidak tentu waktunya. Apalagi pencairannya yang bertahap terkadang cepat dicairkan dan terkadang lambat. Dan kendala yang saya rasakan adalah diharuskannya peserta bidikmisi untuk membuat PKM untuk melihat keaktifan mereka. Setiap tahun tidak semua penerima bidikmisi mengumpulkan PKM dan akhirnya bidikmisi ditunda. Namun PKM ini sepertinya bukan harus jadi satu-satunya bukti keaktifan mahasiswa bidikmisi. Masih banyak hal lain yang bisa dijadikan acuan seperti organisasi kampus atau prestasi yang diraih mahasiswa."

Jadi berdasarkan kelima pendapat dari informan diatas dapat diketahui bahwa selama ini pelaksanaan program bidikmisi di Universitas Pendidikan Ganesha (UNDIKSHA) belum sepenuhnya efektif. Hal ini dikarenakan realisasi dari pelaksanaan bidikmisi di UNDIKSHA ini belum sepenuhnya memenuhi kriteria dari prinsip 3T (tepat sasaran, tepat jumlah, dan tepat waktu). Adapun kendala-kendala yang dirasakan dari masing-masing informan diantaranya :

1. Kurangnya pemahaman mengenai program beasiswa bidikmisi.

2. Kurangnya forum komunikasi.

3. Adanya kewajiban untuk membuat PKM bagi mahasiswa penerima bidikmisi.

\section{Simpulan dan Saran}

\subsection{Simpulan}

Berdasarkan hasil penelitian diatas dapat disimpulkan bahwa penyelengaraan program beasiswa bidikmisi di Universitas Pendidikan Ganesha (UNDIKSHA) belum sepenuhnya efektif. Adapun kendala-kendala ynag dihadapi dari masing-masing informan diantaranya: Kurangnya pemahaman mengenai program beasiswa bidikmisi, kurangnya forum komunikasi, serta adanya kewajiban untuk membuat PKM bagi mahasiswa penerima bidikmisi.

\subsection{Saran}

Adapun saran yang dapat diberikan yaitu sebaiknya pengawasan dalam penyelenggaraan program beasiswa bidikmisi di UNDIKSHA lebih ditingkatkan agar realisasi dari pelaksanaan program beasiswa bidikmisi ini sesuai dengan penerapan prinsip 3T (tepat sasaran, tepat jumlah, dan tepat waktu). 


\section{Daftar Pustaka}

Asra, A., Irawan, P. B., dan Purwoto, A. 2015. Metode Penelitian Survei. Bogor: In Media.

Baskoro, Agung. 2016. Efektivitas Program Bidikmisi di Universitas Negeri Yogyakarta. Skripsi Jurusan IImu Administrasi Negara, Fakultas IImu Sosial, Universitas Negeri Yogyakarta.

Direktorat Jendral Pembelajaran dan Kemahasiswaan, Kementrian Riset, Teknologi, dan Pendidikan Tinggi. Panduan Bidikmisi 2018. Tersedia online pada https://bidikmisi.belmawa.ristekdikti.go.id.

Eldrian, Rizkie P. 2017. Dinamika Dalam Manajemen Beasiswa Bidikmisi (Studi Komparasi pada Universitas Maritim Raja Ali Haji dan Sekolah Tinggi IImu Sosial dan IImu Politik Raja Haji). Tanjungpinang: Universitas Maritim Raja Ali Haji.

Kurniawan, Adi. 2017. Efektivitas Penelenggaraan Program Bantuan Biaya Pendidikan Bidikmisi di Universitas Riau. JOM FISIP, Vol. 4 No. 1.

Rahmawati. 2016. Implementasi Kebijakan Beasiswa Bidikmisi Tahun 2010-2014 (Studi Penelitian di Universitas Diponegoro dan Universitas Negeri Semarang). Journal of Politic and Government Studies, Vol. 5 No. 4.

Sandra, Muhammad. 2017. Pola Perilaku Konsumsi Mahasiswa Bidikmisi 2013 (Studi Tentang Mahasiswa Beasiswa Bidikmisi 2013 Universitas Riau). JOM FISIP, Vol. 4 No. 2.

Silalahi, Ulber. 2012. Metode Penelitian Sosial. Bandung: Refika Aditama.

Situs Internet :

https://ristekdikti.go.id, diakses tanggal 28 Maret 2018.

www.harnas.co, diakses tanggal 28 Maret 2018. 